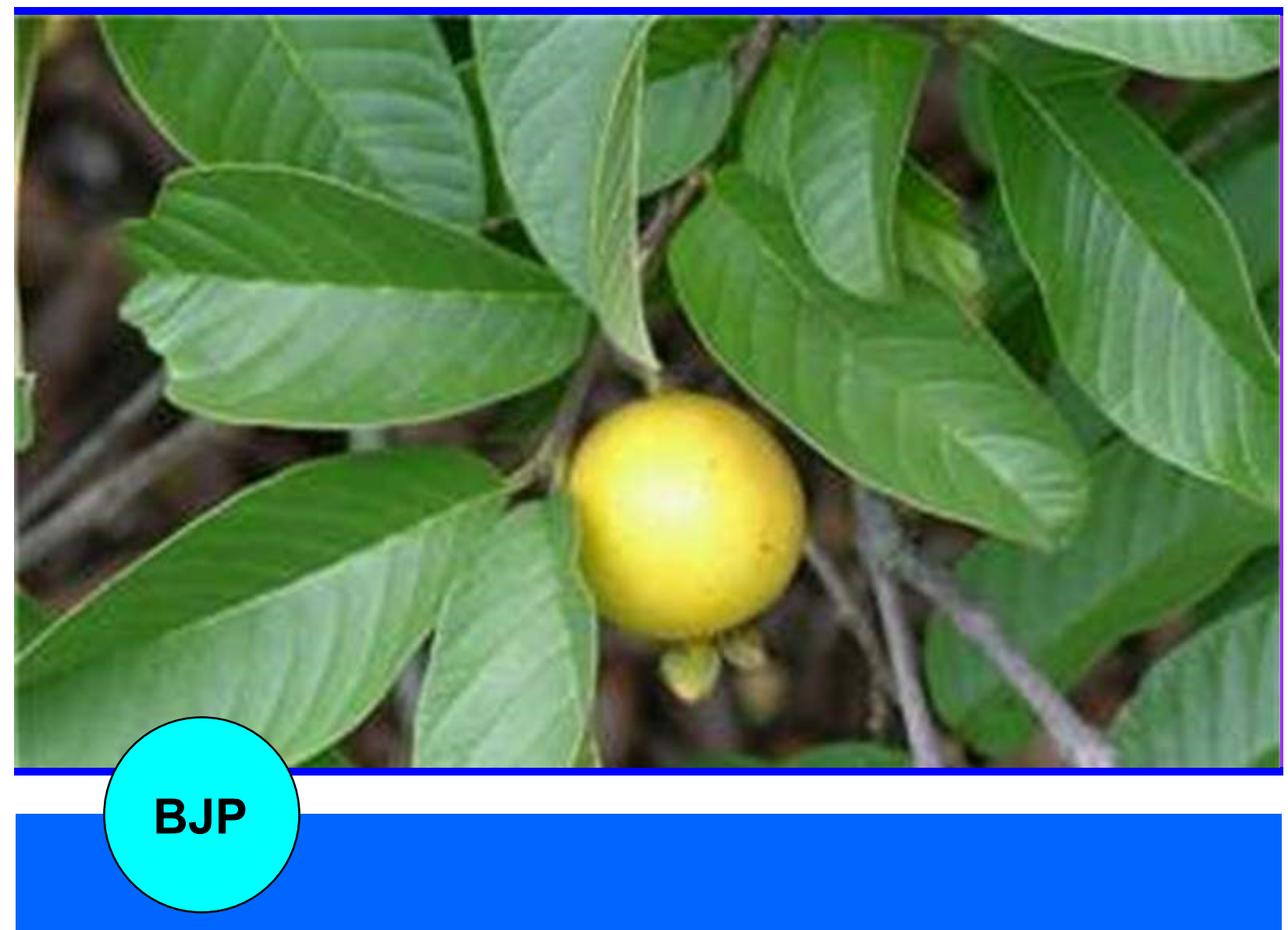

Bangladesh Journal of Pharmacology

Research Article

Pharmacological basis for the medicinal use of Psidium guajava leave in hyperactive gut disorders 
Abstracted/indexed in Academic Search Complete, Agroforestry Abstracts, Asia Journals Online, Bangladesh Journals Online, Biological Abstracts, BIOSIS Previews, CAB Abstracts, Current Abstracts, Directory of Open Access Journals, EMBASE/Excerpta Medica, Global Health, Google Scholar, HINARI (WHO), International Pharmaceutical Abstracts, Open J-gate, Science Citation Index Expanded, SCOPUS and Social Sciences Citation Index

\title{
Pharmacological basis for the medicinal use of Psidium guajava leave in hyperactive gut disorders
}

\author{
Abdul Jabbar Shah',2, Sabira Begum3, Syed Imran Hassan3, Syed Nawazish Ali3, Bina \\ S. Siddiqui3 and Anwarul-Hassan Gilani ${ }^{1}$
}

${ }^{1}$ Natural Products Research Division; Department of Biological and Biomedical Sciences, The Aga Khan University Medical College, Karachi 74800, Pakistan; ${ }^{2}$ Department of Pharmacy, COMSATS Institute of Information Technology, Abbottabad 22060, Pakistan; ${ }^{3}$ HEJ Research Institute of Chemistry, International Center for Chemical and Biological Sciences, University of Karachi, Karachi 75270, Pakistan.

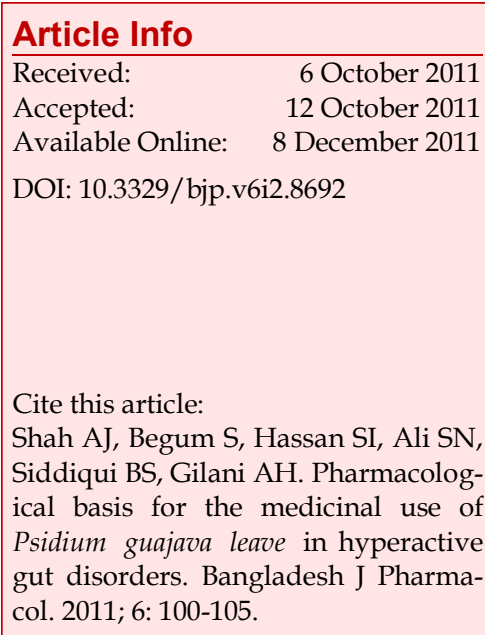

\begin{tabular}{l} 
Abstract \\
\hline Psidium guajava L. is reputed for its medicinal use in hyperactive gut \\
disorders. This study was aimed to investigate mechanism responsible for its \\
medicinal use in diarrhea and gut spasm. In castor oil-induced diarrheal \\
model, the crude extract of $P$. guajava $(100-1,000 \mathrm{mg} / \mathrm{kg})$, provided $20.5-81.1 \%$ \\
protection, similar to loperamide. In isolated rabbit jejunum preparations, \\
crude extract was found more potent against high $\mathrm{K}^{+}$than spontaneous pre- \\
contractions, similar to verapamil, with $\mathrm{EC}_{50}$ values of $0.7(0.4-1.0 ; \mathrm{n}=8)$ and \\
$2.3 \mathrm{mg} / \mathrm{mL}(1.4-3.6 ; \mathrm{n}=8)$, respectively, suggests calcium channel blocking \\
activity, as a possible mode of action. The Ca ${ }^{++}$channel blocking activity was \\
further confirmed when pre-treatment of tissue with crude extract $(0.3-1 \mathrm{mg} /$ \\
mL) caused a rightward shift in the Ca ${ }^{++}$concentration-response curves, \\
similar to verapamil. Loperamide also inhibited spontaneous and high $\mathrm{K}^{+}-$ \\
induced contractions and shifted the Ca ${ }^{++}$curves to the right. These data \\
indicate that crude extract of $P$. guajava possesses Ca ${ }^{++}$antagonist-like \\
constituent(s), which explain its inhibitory effect on gut motility.
\end{tabular}

\section{Introduction}

Psidium guajava L. (family; Myrtaceae) commonly known as "guava" is a native of tropical America and has long been naturalized in Southeast Asia. Different parts of the plant have been used in the indigenous system of medicine for the treatment of various human disorders. The decoction of young leaves and shoot is prescribed as spasmolytic in diarrhea (Lozoya et al., 1994; Duke, 2002; de Wet et al., 2010).

Phytochemical analysis has resulted the isolation and identification of various terpenoids, flavonoids and tannins (Lozoya et al., 1994). Two of pentacyclic triterpenoids of the ursane series, namely ursolic acid, 2a-hydroxyursolic acid, oleanolic acid, maslinic acid and arjunolic acid (Osman et al., 1974) were reported earlier. Among the major constituents are quercetin, myricetin, luteolin and kaempferol (Guti'erreza et al., 2008).

Psidium guajava has been studied for its effect in hyperactive gut disorders, particularly diarrhea and spasm. It has been reported that its leaf extract possesses antidiarrheal (Ojewole et al., 2008) and spasmolytic (Tona et al., 2000) activities. Additionally, the plant extract also possessed, antimalarial (Ponce et al., 1994) activity. In either study, the precise mode of action related to its antidiarrheal and/or antispasmodic effect is not yet clearly understood. This investigation was aimed to explore the underlying mechanism responsible for the medicinal use of $P$. guajava in diarrhea and gut spasm. 


\section{Materials and Methods \\ Plant materials and extraction of crude extract}

Fresh leaves $(20.0 \mathrm{~kg})$ of P. guajava were collected from Karachi region and authenticated by Dr. Mohammad Qaiser, Department of Botany, University of Karachi, Karachi, Pakistan. A voucher specimen (KUH-GH No. 53976) has been deposited in the Herbarium of the same Department.

Plant material free of adulterants were repeatedly extracted (3 times) with EtOH at room temperature and the combined extract was evaporated in rotary evaporator at $35-40^{\circ} \mathrm{C}$ to a semisolid mass, the crude extract of $P$. guajava. The extract was solubilized in normal saline and distilled water for the in vivo and in vitro experiments, respectively.

\section{Drugs and standards}

The following reference chemicals were obtained from the sources specified: acetylcholine chloride, loperamide hydrochloride, verapamil hydrochloride, potassium chloride (Sigma Chemical Company, U.S.A.) and castor oil (Karachi Chemical Industries, Pakistan). All chemicals used were of the highest purity grade. Stock solutions of all the chemicals were made in distilled water and the dilutions were made fresh in normal saline on the day of experiment.

\section{Animals}

Experiments performed complied with the rulings of the Institute of Laboratory Animal Resources, Commission on Life Sciences, National Research Council (National Research Council, 1996) and were approved by the Ethical Committee of the Aga Khan University, Karachi, Pakistan. Balbc mice (20-25 g) and local rabbits $(1.5-2 \mathrm{~kg})$ of either sex used in the study were bred and housed in the animal house of the Aga Khan University under controlled environment $\left(23-25^{\circ} \mathrm{C}\right)$. Animals were given tap water ad libitum and a standard diet.

\section{Castor oil-induced diarrhea}

The in vivo antidiarrheal activity of the extract was conducted following the methods previously described (Awouters et al., 1978; Jebunnessa, 2009; Shah et al., 2011). In the present study Balbc albino mice were fasted for 18 hours. The animals divided in five groups, housed in five steel cages with five in each and the bottom of each cage was covered with blotting sheet. The first group received saline as the vehicle control (10 $\mathrm{mL} / \mathrm{kg}$, orally) and acted as the negative control. The doses of the crude extract were selected on a trial basis and administered orally $(100,300$ and 1,000 mg/kg) by intra-gastric feeding needle as a suspension to three groups of animals. The fifth group received loperamide $(10 \mathrm{mg} / \mathrm{kg})$ orally, which served as a positive control. One hour after treatment, each animal received $10 \mathrm{~mL} /$ $\mathrm{kg}$ of castor oil orally and was then observed for defecation. The presence of diarrheal droppings was noted in blotting sheets in the individual cages for 4 hours after challenged with castor oil. Percent protection against the castor oil-induced diarrhea was calculated based on the number of dry feces in each cage in comparison to the wet.

\section{Isolated tissue preparations}

The isolated tissue experiments were carried out, as previously described (Gilani et al., 2005; Shah et al., 2011). Rabbits had free access to water but were fasted for 24 hours before the experiment. The animals were sacrificed by cervical dislocation, the abdomen was cut open and the jejunal portion isolated out. Preparations 2 $\mathrm{cm}$ long were mounted in $10 \mathrm{~mL}$ tissue baths containing Tyrode's solution maintained at $37^{\circ} \mathrm{C}$ and aerated with a mixture of $5 \%$ carbon dioxide in oxygen (carbogen). The composition of Tyrode's, in $\mathrm{mM}$, was: $\mathrm{KCl} 2.7$, $\mathrm{NaCl}$ 136.9, $\mathrm{MgCl}_{2}$ 1.1, $\mathrm{NaHCO}_{3}$ 11.9, $\mathrm{NaH}_{2} \mathrm{PO}_{4}$ 0.4, glucose 5.6 and $\mathrm{CaCl}_{2} 1.8$ (pH 7.4). A preload of $1 \mathrm{~g}$ was applied to each tissue and were kept undisturbed for an equilibrium period of $30 \mathrm{~min}$. After equilibration, control responses to a sub-maximal concentration of acetylcholine $(0.3 \mathrm{mM})$ were obtained and the tissue presumed stable only after the reproducibility of the said responses.

Under these experimental conditions, rabbit jejunum exhibits spontaneous rhythmic contractions, allowing testing the relaxant (spasmolytic) activity directly without the use of an agonist or spasmogen (Gilani et al., 2005).

\section{Determination of calcium antagonist activity}

To assess whether the spasmolytic activity of the test substances was mediated through $\mathrm{Ca}^{++}$channel blockade, high concentration of $\mathrm{K}^{+}(80 \mathrm{mM})$, as $\mathrm{KCl}$, was used to depolarize the preparations (Farre et al., 1991), which produced a sustained contraction. Plant extract and standards were then added in a cumulative fashion to obtain concentration-dependent inhibitory responses. The relaxation of intestinal preparations, pre -contracted with $\mathrm{K}^{+}$was expressed as percent of the control pre-contraction.

To confirm the $\mathrm{Ca}^{++}$antagonist activity of test substances, the tissues were allowed to stabilize in normal Tyrode's solution, which was then replaced with $\mathrm{Ca}^{++}$ free Tyrode's solution containing EDTA $(0.1 \mathrm{mM})$ for 30 min in order to remove $\mathrm{Ca}^{++}$from the tissues. This solution was further replaced with $\mathrm{K}^{+}$-rich and $\mathrm{Ca}^{++}$ free Tyrode's solution, having the following composition: $\mathrm{KCl} 50, \mathrm{NaCl} 91.04, \mathrm{MgCl}_{2}$ 1.05, $\mathrm{NaHCO}_{3}$ 11.90, $\mathrm{NaH}_{2} \mathrm{PO}_{4}$ 0.42, glucose 5.55 and EDTA $0.1 \mathrm{mM}$. Following an incubation period of $30 \mathrm{~min}$, control concentration-response curves of $\mathrm{Ca}^{++}$were obtained. When the control curves of $\mathrm{Ca}^{++}$were found superimposable (usually after two cycles), the tissue were then pretreated with the plant extract for $60 \mathrm{~min}$ to test 
the possible $\mathrm{Ca}^{++}$channel blocking effect. The $\mathrm{Ca}^{++}$ curves were reconstructed in the presence of different concentrations of the test material.

\section{Statistics}

All the data expressed are mean \pm standard error of the mean (SEM) and the median effective concentrations $\left(\mathrm{EC}_{50}\right)$ values are given with $95 \%$ confidence intervals (CI). The statistical parameter applied is the student $t-$ test with $\mathrm{p}<0.05$ noted as significantly different (GraphPad program, GraphPad, San Diego, Ca, USA) and concentration response curves were analyzed by non-linear regression (GraphPAD program).

\section{Results and Discussion}

Based on the medicinal use of P. guajava in hyperactive gut disorders, such as diarrhea and spasm (Lozoya et al., 1994; Duke, 2002; de Wet et al., 2010), its crude extract was screened for antidiarrheal effect in mice. The crude extract provided protection from diarrhea in castor oil-induced diarrhea, similar to loperamide, a standard antidiarrheal agent (Reynolds et al., 1984). Both extract and loperamide inhibited significantly $(p<0.05)$ the frequency of defecation as well as wetting of feces when compared with the untreated group (i.e. mice received neither crude extract, nor loperamide, but castor oil only). The percent protection provided by the crude extract and loperamide was $20.5-81.1 \%$ and $97.3 \%$, respectively (Table I). Verapamil, a standard calcium channel blocker (Godfraind et al., 1986) also provided protection (35.6-82.3\%) from castor oilinduced diarrhea.

The induction of diarrhea by castor oil results from the action of recinoleic acid formed in the hydrolysis of the oil (Iwao and Terada, 1962), which produces changes in the transport of water and electrolytes resulting in a hypersecretory response and generation of a giant contraction of the intestine (Croci et al., 1997). Thus, a potential antidiarrheal agent may exhibit its antidiarrheal effect by inhibiting either gut motility and or electrolyte out flux (diarrheal droppings; Croci et al., 1997). The protective effect of the crude extract against the castor oil-induced diarrhea in mice, similar to loperamide and verapamil, suggests that it has an inhibitory effect either on contraction and or on electrolyte out flux.

There are studies available on the antidiarrheal and antispasmodic activities of the crude extract of $P$. guajava showing that the antidiarrheal effect of the extract was attributed either to its antibacterial (Coutino et al., 2001; Neira and Ramirez, 2005), antisecretory (Gutierrez et al., 2008) or spasmolytic (Morales et al., 1994; Ojewol et al., 2008) activities. Morales et al. (1994) reported that the spasmolytic effect of quercetin, one of the major constituents of all parts of P. gujava, may be responsible for the intestinal inhibitory activity and hence for the antidiarrheal action. However, Ojewol et al. (2008) attributed atropine-like spasmoyltic activity of crude extract to its antidiarrheal effect. To probe the precise mechanism of the spasmolytic effect of the extract, further study was carried out on gut motility in isolated spontaneously contracting rabbit jejunum, where cumulative addition of crude extract, loperamide and verapamil caused concentration-dependent inhibition of the spontaneous contractions (Figure 1), with $\mathrm{EC}_{50}$ values of $2.28 \mathrm{mg} / \mathrm{mL}(1.4-3.6), 1.6 \mu \mathrm{M}(1.2-2.2)$ and $0.2 \mu \mathrm{M}(0.1-0.3)$, respectively (Figure 2 ). This shows smooth muscle relaxant (spasmolytic) activity. The contraction of smooth muscle preparations, including rabbit jejunum, is depend upon an increase in the cytoplasmic free $\left[\mathrm{Ca}^{++}\right]$, which activates the contractile elements (Karaki and Weiss, 1983). The increase in intracellular $\mathrm{Ca}^{++}$occurs either via influx through voltage-dependent $\mathrm{Ca}^{++}$channels or its release from

Table I

Effect of the crude extract of the leaves of Psidium gujava, verapamil and loperamide on castor oil-induced diarrhea in mice

\begin{tabular}{|lcccr|}
\hline Group & Dose & $\begin{array}{c}\text { Total number of feces in } \\
4 \text { hours }\end{array}$ & $\begin{array}{c}\text { Total number of wet feces in } \\
4 \text { hours }\end{array}$ & Protection (\%) \\
\hline Control (saline) & $10 \mathrm{~mL} / \mathrm{kg}$ & $14.8 \pm 1.1$ & $0.2 \pm 0.3$ & $99.3 \pm 0.9$ \\
Castor oil & $10 \mathrm{~mL} / \mathrm{kg}$ & $11.8 \pm 0.8$ & $11.6 \pm 0.8$ & $1.3 \pm 0.8$ \\
+ extract & $100 \mathrm{mg} / \mathrm{kg}$ & $19.8 \pm 1.0$ & $14.2 \pm 1.0$ & $20.5 \pm 1.2^{\mathrm{a}}$ \\
+ extract & $300 \mathrm{mg} / \mathrm{kg}$ & $20.8 \pm 1.1$ & $9.2 \pm 0.6$ & $39.7 \pm 3.2^{\mathrm{b}}$ \\
+ extract & $1,000 \mathrm{mg} / \mathrm{kg}$ & $13.8 \pm 1.2$ & $2.4 \pm 0.9$ & $81.1 \pm 3.2^{\mathrm{c}}$ \\
+ verapamil & $3 \mathrm{mg} / \mathrm{kg}$ & $11.8 \pm 1.7$ & $64.5 \pm 0.9$ & $35.6 \pm 3.5^{\mathrm{a}}$ \\
+ verapamil & $10 \mathrm{mg} / \mathrm{kg}$ & $13.8 \pm 1.7$ & $40.4 \pm 4.6$ & $59.6 \pm 4.6^{\mathrm{b}}$ \\
+ verapamil & $30 \mathrm{mg} / \mathrm{kg}$ & $18.2 \pm 3.3$ & $17.7 \pm 4.5$ & $82.3 \pm 4.5^{\mathrm{c}}$ \\
+ loperamide & $10 \mathrm{mg} / \mathrm{kg}$ & $8.8 \pm 1.2$ & $0.4 \pm 0.3$ & $97.3 \pm 1.7$ \\
\hline Mean \pm SEM; $\mathrm{n}=5 ;$ a $<<0.05, \mathrm{~b}<<0.01, \mathrm{c}<<0.001$ vs. control, Student's t-test & & \\
\hline
\end{tabular}




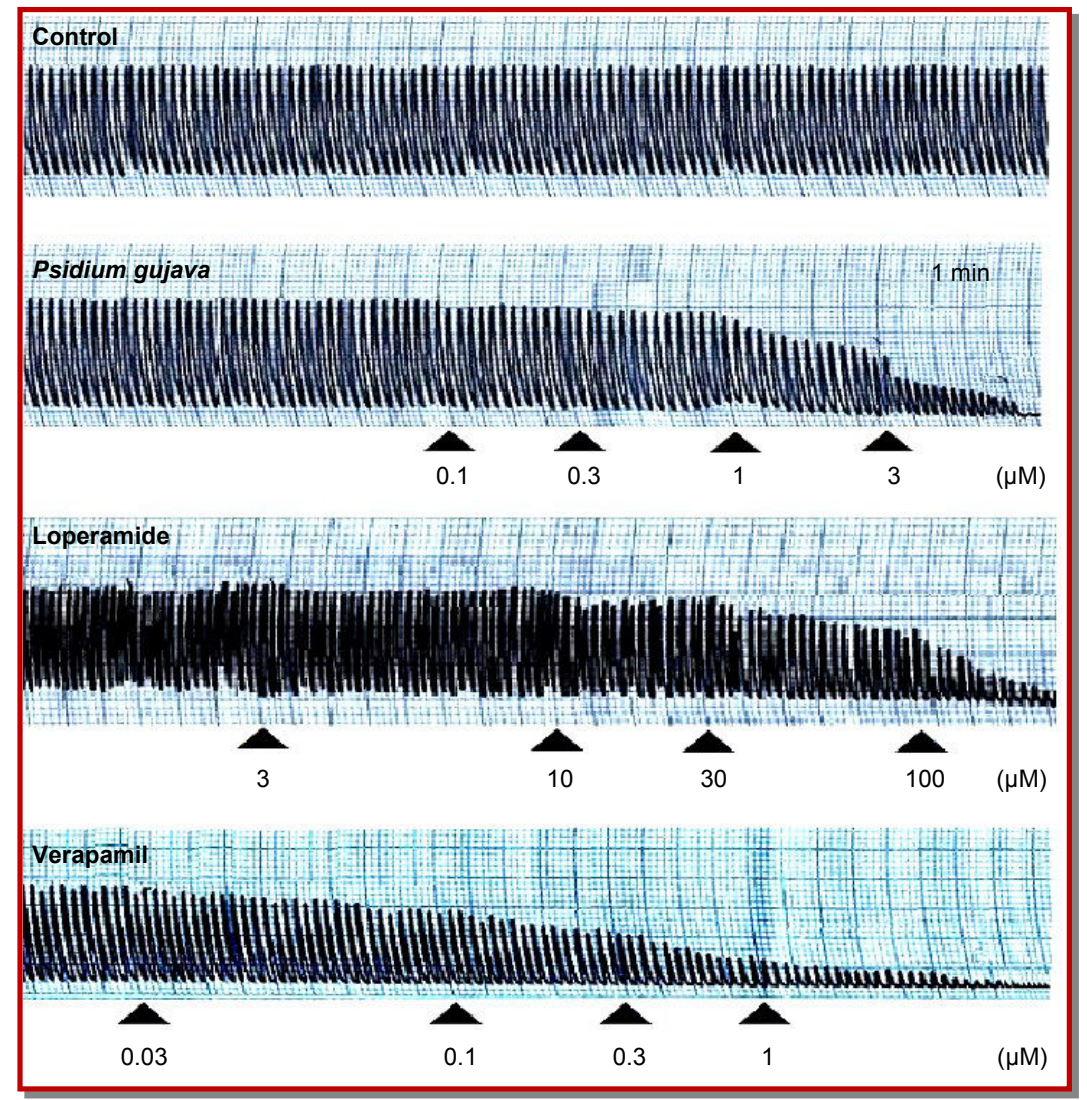

Figure 1: A typical tracing showing the spasmolytic effects of the crude extract of P. gujava, loperamide and verapamil on spontaneous contractions in isolated rabbit jejunum preparation

intracellular stores in the sarcoplasmic reticulum. Periodic depolarization and repolarization regulates the spontaneous movements of the intestine and at the height of depolarization, the action potential appears as a rapid influx of $\mathrm{Ca}^{++}$via voltage dependent channels (Brading, 1981). Thus, the inhibitory effect of crude extract on spontaneous movements of rabbit jejunum may appear to be due to a CCB effect, possibly, due to interference of $\mathrm{Ca}^{++}$influx through $\mathrm{Ca}^{++}$channels.

We previously observed that the spasmolytic constituents present in different medicinal plants mediate their effect usually through a CCB effect (Gilani et al., 2005; Shah et al., 2010; Shah et al., 2011). To see, whether the spasmolytic effect of the $P$. guajava observed in this study is also mediated through a $\mathrm{Ca}^{++}$antagonist-like effect, a high concentration of $\mathrm{K}^{+}(80 \mathrm{mM})$ was added to the tissues bath, which is known to produce sustained contraction through opening of voltage dependent $\mathrm{Ca}^{++}$channels. The crude extract was then added in a cumulative fashion, where it was found more potent against high $\mathrm{K}^{+}$pre-contractions than spontaneous contractions, with respective $\mathrm{EC}_{50}$ value of $0.7 \mathrm{mg} / \mathrm{mL}$ (0.4-1.0), similar to verapamil and loperamide (Figure 2). A substance, which can inhibit high $\mathrm{K}^{+}$-induced contractions is therefore, possibly considered to be a $\mathrm{Ca}^{++}$antagonist (Godfraind et al., 1986). Thus, the inhibition of high $\mathrm{K}^{+}$ pre-contractions of rabbit jejunum by crude extract may reflect the restricted $\mathrm{Ca}^{++}$entry via voltage-dependent channels. This hypothesis was further strengthened when pre-treatment of the tissues with plant extract $(0.3$ $-1 \mathrm{mg} / \mathrm{mL}$ ) caused a rightward shift in the $\mathrm{Ca}^{++}$curves (Figure 2), similar to verapamil. Pretreatment of the tissues with loperamide also caused a rightward shift in the $\mathrm{Ca}^{++}$curves (Figure 2), which is in accordance to its known $\mathrm{Ca}^{++}$antagonist effect at antidiarrheal doses (Reynolds et al., 1984). These data indicate that plant extract possesses a $\mathrm{Ca}^{++}$antagonist effect, similar to verapamil or loperamideand and thus provides sound pharmacological basis to its antidiarrheal and antispasmodic effects, as the $\mathrm{Ca}^{++}$antagonists are considered useful in diarrhea and gut spasms (Brunton, 1996). This is the first functional study of its kind on the gut motility with possible mode of action explored and the earlier studies on antibacterial action of the plant is of added benefit to the plant, thus making the plant more effective in a diarrhea of wide range etiology including infectious and non-infectious.

In summary, this study shows that the crude extract of Psidium guajava possesses antidiarrheal along with antispasmodic effects, mediated possibly through $\mathrm{Ca}^{++}$ channel blockade, which provides sound pharmacological base to its medicinal use in diarrhea and gut 

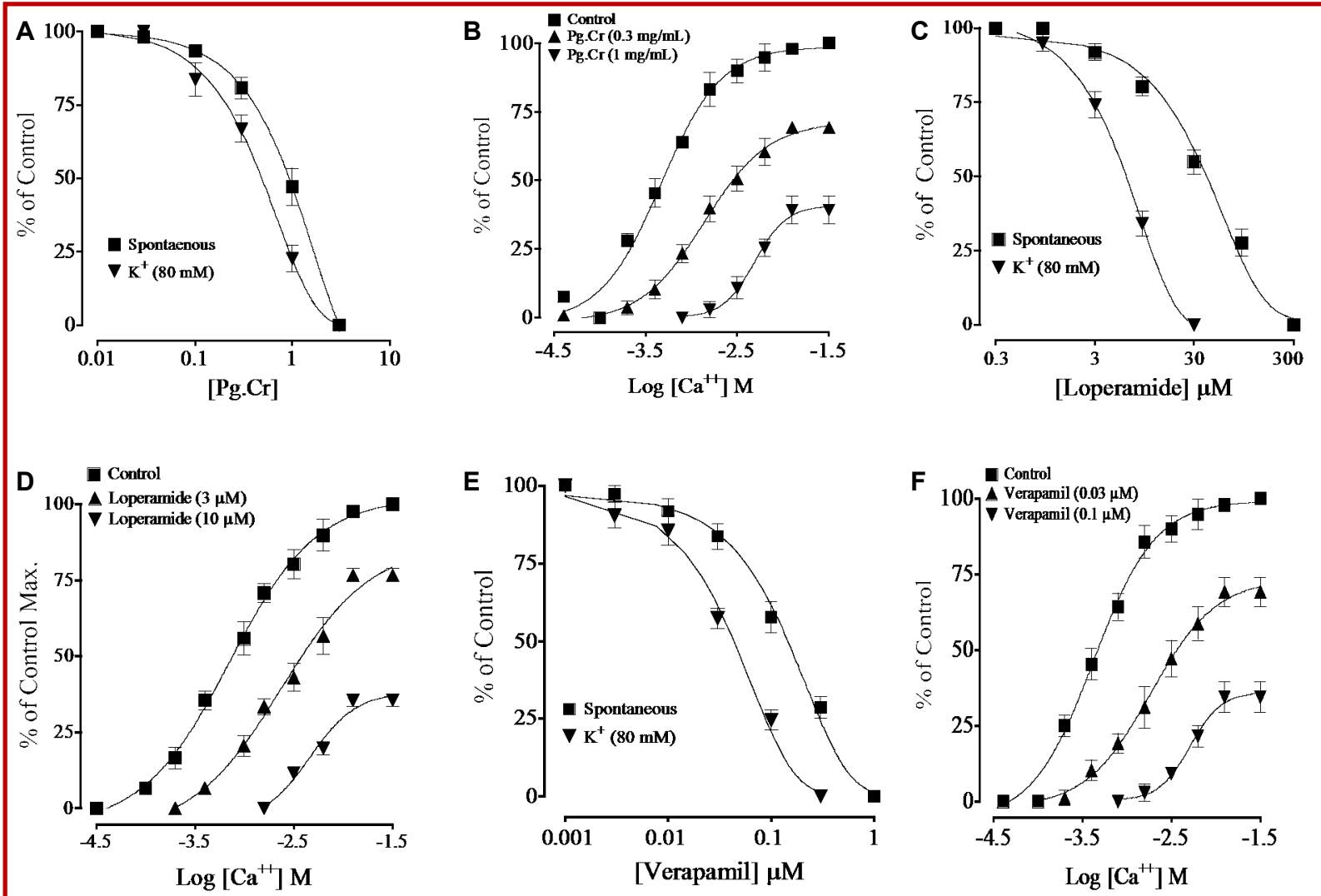

Figure 2. Concentration-response curves of; (A) the crude extract of Psidium gujava (Pg.Cr), (C) loperamide, and (E) verapamil on spontaneous and high $\mathrm{K}^{+}(80 \mathrm{mM})$-induced contractions. $(\mathrm{B}, \mathrm{D}$ and $\mathrm{F})$ depict the effect on $\mathrm{Ca}^{++}$concentration-response curves in the absence and presence of different concentrations of Pg.Cr, loperamide and verapamil, respectively, in isolated rabbit jejunum preparations. Values shown are \pm SEM $(n=5-7)$

spasms, though additional mechanism(s) cannot be ruled out.

\section{Acknowledgement}

This study was carried out with the partial support from the Higher Education Commission, Government of Pakistan.

\section{References}

Awouters F, Niemegeers CJE, Lenaerts FM, Janssen PAJ. Delay of castor oil diarrhea in rats, a new way to evaluate inhibitors of prostaglandin biosynthesis. J Pharm Pharmacol. 1978; 30: 41-45.

Brading AF. How do drugs initiate contraction in smooth muscles? Trends Pharmacol Sci. 1981; 2: 261-65.

Brunton LL. Agents affecting gastrointestinal water flux and motility; emesis and antiemetics; bile acids and pancreatic enzymes. In: Goodman and Gillman's The Pharmacological Basis of Therapeutics. Hardman JG, Limbird LE, Molinoff PB (eds). New York, McGraw Hill, 1996.

Croci T, Landi M, Almond-Alt X, Le F, Maffrand JP, Manara L. Role of tachykinins in castor oil induced diarrhea in rats. $\mathrm{Br}$
J Pharmacol. 1997; 121: 375-80.

Coutino RR, Hern'andez CP, Giles RH. Lectins in fruits having gas-trointestinal activity: Their participation in the hemagglutinating property of Escherichia coli O157:H7. Arch Med Res. 2001; 32: 251-57.

de Wet H, Nkwanyana MN, van Vuuren SF. Medicinal plants used for the treatment of diarrhea in northern Maputaland, KwaZulu-Natal Province, South Africa. J Ethnopharmacol. 2010; 130: 284-89.

Duke JA. Handbook of medicinal herbs. London, CRC Press, 2002.

Farre AJ, Columbo M, Fort M, Gutierrez B. Differential effects of various $\mathrm{Ca}^{++}$antagonists. Gen Pharmacol. 1991; 22: 177-81.

Gilani AH, Shah AJ, Muhammad NG, Kashif M. Pharmacological basis for the use of turmeric in gastrointestinal and respiratory disorders. Life Sci. 2005; 76: 3089-3105.

Godfraind T, Miller R, Wibo M. Calcium antagonism and calcium entry blockade. Pharmacol Rev. 1986; 38: 321-416.

Guti'erreza RMP, Mitchell S, Solis RV. Psidium guajava: A review of its traditional uses, phytochemistry and pharmacology. J Ethnopharmacol. 2008; 117: 1-27.

Iwao I, Terada Y. On the mechanism of diarrhea due to castor 
oil. Jap J Pharmacol. 1962; 12: 137-45.

Jebunnessa, Uddin SB, Mahbub-Uz-Zaman M, Akter R, Ahmed NU. Antidiarrheal activity of ethanolic bark extract of Mitragyna diversifolia. Bangladesh J Pharmacol. 2009; 4: $144-46$.

Karaki H, Weiss G. Calcium release in smooth muscles. Life Sci. 1983; 42: 111-22.

Lozoya X, Meckes M, Abou-Zaid M, Tortoriello J, Nozzolillo C, Arnason JT. Quercetin glycosides in Psidium guajava L. leaves and determination of a spasmolytic principle. Arch Med Res. 1994; 25: 11-15.

Morales MA, Tortoriello J, Meckes M, Paz D, Lozoya X. Calcium-antagonist effect of quercetin and its relation with the spasmolytic properties of Psidium guajava L. Arch Med Res. 1994; 25: 17-21.

National Research Council. Guide for the care and use of laboratory animals. Washington DC, National Academy Press, 1996.

Neira GA, Ramirez GMB. Actividad antimicrobiana de extractos de dos especies de guayaba contra Sterptococcus mutans y Escherichia coli. Actualidades Biologicas. 2005; 27: 27-30.
Ojewole JA, Awe EO, Chiwororo WD. Antidiarrheal activity of Psidium guajava Linn. (Myrtaceae) leaf aqueous extract in rodents. J Smooth Muscle Res. 2008; 44: 195-207.

Osman AM, Younes ME, Sheta AE. Triterpenoids of the leaves of Psidium guajava. Phytochemistry 1974; 13: 2015-16.

Reynolds IJ, Gould RJ, Synder SH. Loperamide blockade of calcium channel as mechanism for antidiarrheal effects. J Exp Pharmacol Ther. 1984; 231: 628-32.

Shah AJ, Bhulani NN, Khan SH, Gilani AH. Antidiarrhoeal and antispasmodic effects of Mentha longifolia are mediated through calcium channel blockade. Phytother Res. 2010; 24: 1392-97.

Shah AJ, Zaidi MA, Hamidullah SH, Gilani AH. Antidiarrheal and antispasmodic activities of Vincetoxicum stocksii are mediated through calcium channel blockade. Bangladesh J Pharmacol. 2011; 6: 46-50.

Tona L, Kambu K, Ngimbi N, Mesia K, Penge O, Lusakibanza M, Cimanga K, De Bruyne T, Apers S, Totte J, Pieters L, Vlietinck AJ. Antiamoebic and spasmolytic activities of extracts from some antidiarrheal traditional preparations used in Kinshasa, Congo. Phytomedicine 2000; 7: 31-38. 